\title{
Behavior Changesin Older PersonsCaused byUsing Wood Products in Assisted Living
}

\author{
Anme T. ${ }^{1, *}$, Watanabe T. MA ${ }^{1}$, Tokutake K. MA ${ }^{1}$, Tomis aki E. MA ${ }^{1}$, Mochizuki H. MA ${ }^{1}$, Tanaka E. MA ${ }^{1}$, \\ Wu B. MA ${ }^{1}$, Shinohara R. ${ }^{1}$, Sugis awa Y. ${ }^{1}$, Tada $C^{2}{ }^{2}$, Mats ui T. $^{3}$, Asada S. ${ }^{4}$ \\ ${ }^{1}$ Faculty of Medicine, University of Tsukuba, Ibaragi, Japan \\ ${ }^{2}$ Tokyo Toy Museum, Tokyo, Japan \\ ${ }^{3}$ Faculty of Wood, Gifu Academy of Forest Science and Culture, Gifu, Japan \\ ${ }^{4}$ Faculty of Education, Saitama Univ ersity, Saitama, Japan
}

\begin{abstract}
The purpose of this studywas to clarify the effects of using wood products in older persons' environment by means of an intervention study. The participants were 44 older persons in a single assisted-living facility. Evaluators observed the participants' behavior at 5 points: (1) not using any products (baseline), (2) using plastic tables and chairs, (3) using wood tables and chairs, (4) using wood tableware, (5) continually using wood products for 5 weeks. Health care professionals evaluated the older persons' health status and activities of daily living through regular observation.The results indicated that regular use of wood products significantly increased the social interactionand activity levels of the elder. Thus, use of wood products may enhance the possibility of preventing mental and physical decline in the frail elderly.
\end{abstract}

Keywords Interaction, Wood Products, Old Person, Evaluation, Scale

\section{Introduction}

The effects of natural products, such as those made from wood, are of interest worldwide because people are aware that humans need an ecologically friendly, sustainable society. Previous research has explored the healing [1,2] and safety effects [3,4]of wood products. Few studies, however, have evaluated the actual change that the use of such products might make in the behavior of older persons in assisted living.

The increasing number of older persons with dementia and societal maladjustment requires society to prepare appropriate living environments for those people. For decades, researchers, practitioners, and caregivers have been attracted to studyingthe prevention of a decline in social competence. Social competence is determined by complex interactionsbetweenpersons and their living environments, peer relationships, and the larger sociocultural environment[5]. It is defined as the ability to understand others in the context of social interaction and to engage in s mooth communication with them.

The factors comprising "social competence" have been a frequent topic of research worldwide for some decades, andsome common factors have emerged from the studies. Forexample, SSRS [8] identified three factors-namely,

* Corresponding author:

anmet@md.tsukuba.ac.jp (Anme T.)

Published online at http://journal.sapub.org/phr

Copyright (C) 2012 Scientific \& Acad emic Publishing. All Rights Reserved cooperation, self-control, and assertion. Caldare lla [9] mentioned five factors-peer relations, compliance, self-management, assertion, and academic success-while Elksninand Elksnin[10] offer such aspects as interpersonal, teacher-pleasing, self-related communication, and assertiveness; Kolb [11] also defines five factors: peer and group interaction, problem solving/decision making, self-management, communication, and as sertion. These lists have three factors in common: empathy/coordination with peers, self-regulation, and assertion.

The social competence of adults has been evaluated with a number of scales that employ various factors: the Social Skills Inventory (SSI) [12] (the six factors are emotional expressivity, emotional sensitivity, emotional control, social expressivity, social sensitivity, social control); ENDCOREs [13] (self-control, expressivity, sensitivity, assertiveness, responsiveness and regulation); Adult Behavior Checklist for Ages 18-59 (ASEBA) [14,15] (adaptive functioning, empirically based syndromes, substance use, internalizing, externalizing, and total problems); and the Weinberger Adjustment Inventory (WAI) [16] (distress, anxiety, depression, low self-esteem, low well-being, self-restraint, suppression of aggression, impulse control, responsibility, and consideration of others).

These factors involved in social competence, along with the scales for evaluating it, indicate clearly that social competence should be assessed by the interaction between persons and their social environment. Many researchers do focus on measuring the quality of living environments and care, based on the theory that living environment is signifi- 
cantly related to older persons' health. However, methodologies that consider persons in conjunction with their social environment across developmental stages have not yet been well developed.

Two instruments have been designed toevaluate persons' living environment within their natural settings, as well as anindividual's emotional and verbal responsiveness to otherpersons, and the acceptance of another person's behavior. The Alzheimer's Disease Related Quality of Life (ADRQL) [5,6] andthe Interaction Rating Scale Advanced (IRSA)[7] are often used in research related to social competence and quality of life for the frail elderly.

The ADRQL and IRSAboth evaluate persons' living environ ment within their natural settings, as well as a person's emotional and verbal responsiveness to otherpersons, and the acceptance of another person's behavior.

Previous research has alluded to the positive effects of wood products:they are alleged to have a relaxing effect and to reduce fatigue through the chemical phytoncide [1]. In addition, visual comfort is attained because of wood's ultraviolet absorptivity and its emotional harmony [2-4]. The purpose of this study is to clarify the effects of using wood products on older persons through an intervention study. It is meaningful for health professionals to know how a living environment with wood products influences older persons' social interaction and quality of life.

\section{Methods}

\subsection{Participants}

All of the participants in our study were ina single assisted living facility in the Shizuoka Prefecture, Japan. We excluded members who were severely demented or too disabled to move by themselves. Among the 47 residents of the facility, 44 participated the study. There were 15 men and 29 wo men, ranging in age from 71 to 96 years.

This study was approved by the ethics committee of the Art Education Council. In order to comply with ethical standards, signed informed consent forms were obtained from all participants at the beginning, and they were made aware that they had the right to withdraw from the experiment at anytime. To maintain the confidentiality of the personal information of the participants, a personal ID system was used to protect personal information. Further, all the image data were stored on a password-protected disk; only the researchers who were granted permission were given access to the data.

\subsection{Me as ures}

TheADRQL[5,6]consists of 47 items grouped into 5 domains connected with the quality of life of the frail elderly as assessed by a caregiver or health care professional. These domains are social interaction, awareness of self, feelings and mood, enjoyment of activities, and response to surroundings. Each item is weightedby caregivers and experts according to the importance attached to it for quality of life. Item weights are summed to yield a score for each subscale, and these subscale scores are then summed to yield a total score.

The IRSA[7]consists of 92 items grouped into 6 domains connected with social competence as assessed through 5-minute observations by evaluators, whohad acquired a reliability of over $90 \%$ consistency before the study. These domains are self-control, exp ressivity, sensitivity, assertiveness, responsiveness, and regulation.

Each subscale assesses the presence of behaviors $(1=$ Yes, $0=\mathrm{No}$ ), and the sum of all items in the subscale provides the overall behavior score.

To avoid duplication, we used the items from only three of the domains of sensitivity-empathy, responsiveness to social engagement, and expressivity as self-expression.

\subsection{Proce dure}

The evaluators observed the participants' behaviorin their everyday life at five points: (1) not using any products (baseline, Photo1);(2) using plastics tables and chairs (Photo2);(3) using wood tables and chairs(Photo3);(4) using wood tableware(Photo4);(5) continual use of wood products for five weeks. To score the behavior, two evaluators coded the participants' observed behaviors. In addition, healthcare professionals evaluated older persons' health status and activitiesofdaily living based on regular observation at the assisted living facility.

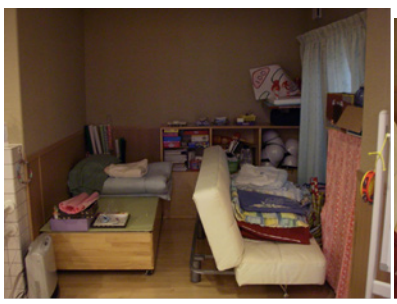

Photo 1. Baseline

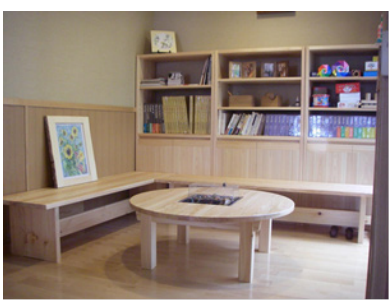

Photo 3. Wood productuse

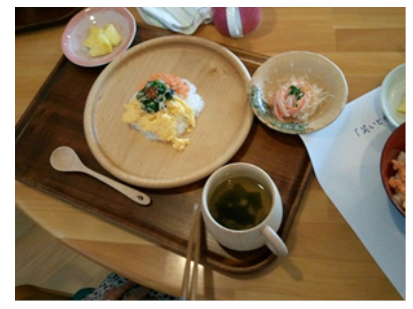

Photo 4. Wood tableware use

\section{Results}


Figure1 shows thechangesin elderly persons' behavior score according with the stages indicated above, from(1) baseline through(5) continualuse of wood products for 5 weeks.
The scores for Response to surroundings, Empathy, and Self-expression, in addition to the total scores,were significantly increased after using wood products,as observable through the scores kept over5 weeks (Table 1).

Table 1. Elderly persons' score at each stage

\begin{tabular}{|c|c|c|c|c|c|c|c|}
\hline \multicolumn{2}{|l|}{ Item } & Baseline & $\begin{array}{c}\text { Plastic } \\
\text { table/chair }\end{array}$ & $\begin{array}{c}\text { Wood } \\
\text { table/chiar }\end{array}$ & $\begin{array}{c}\text { Wood } \\
\text { tableware }\end{array}$ & $\begin{array}{c}\text { Wood } \\
\text { table/chair/tableware }\end{array}$ & $\mathrm{p}$ \\
\hline \multirow{2}{*}{ Social interaction } & median & 58.3 & 66.7 & 75.0 & 66.7 & 66.7 & \multirow{2}{*}{ n.s. } \\
\hline & $25 \%-75 \%$ & $50.0-75.0$ & $41.7-81.2$ & $52.1-83.3$ & $50.0-83.3$ & $41.7-83.3$ & \\
\hline \multirow{2}{*}{ Awareness of self } & median & 62.5 & 75.0 & 75.0 & 75.0 & 75.0 & \multirow{2}{*}{ n.s. } \\
\hline & $25 \%-75 \%$ & $25.0-75.0$ & $62.5-84.4$ & $62.5-87.5$ & $56.2-87.5$ & $50.0-87.5$ & \\
\hline \multirow{2}{*}{ Enjoyment of activities } & median & 83.3 & 50.0 & 66.7 & 66.7 & 83.3 & \multirow{2}{*}{ n.s. } \\
\hline & $25 \%-75 \%$ & $16.7-100$ & $16.7-66.7$ & $16.7-66.7$ & $33.3-83.3$ & $33.3-83.3$ & \\
\hline \multirow{2}{*}{ Feeling and mood } & median & 86.7 & 80.0 & 93.3 & 86.7 & 93.3 & \multirow{2}{*}{ n.s. } \\
\hline & $25 \%-75 \%$ & 73.3-93.3 & $73.3-93.3$ & 73.3-98.3 & 73.3-93.3 & $73.3-93.3$ & \\
\hline \multirow{2}{*}{ Response to surroundings } & median & 71.4 & 85.7 & 100.0 & 100.0 & 100.0 & \multirow{2}{*}{0.055} \\
\hline & $25 \%-75 \%$ & 28.6-71.4 & 71.4-100 & $85.7-100$ & $85.7-100$ & $85.7-100$ & \\
\hline \multirow{2}{*}{ Empathy } & median & 0.0 & 71.4 & 100.0 & 100.0 & 85.7 & \multirow{2}{*}{0.031} \\
\hline & $25 \%-75 \%$ & $0.0-0.0$ & 42.9-100 & 71.4-100 & $57.1-100$ & $57.1-100$ & \\
\hline \multirow{2}{*}{ Social engagement } & median & 0.0 & 50.0 & 66.7 & 83.3 & 83.3 & \multirow{2}{*}{ n.s. } \\
\hline & $25 \%-75 \%$ & $0.0-0.0$ & $16.7-83.3$ & $50.0-100$ & $25.0-100$ & $33.3-100$ & \\
\hline \multirow{2}{*}{ Self-expression } & median & 0.0 & 50.0 & 75.0 & 75.0 & 75.0 & \multirow{2}{*}{0.006} \\
\hline & $25 \%-75 \%$ & $0.0-0.0$ & $25.0-75.0$ & $50.0-75.0$ & $37.5-75.0$ & $25.0-100$ & \\
\hline \multirow{2}{*}{ Total } & median & 39.1 & 66.0 & 79.3 & 72.2 & 75.4 & \multirow{2}{*}{0.046} \\
\hline & $25 \%-75 \%$ & $33.3-52.0$ & $41.4-80.7$ & $60.4-85.9$ & $58.3-90.0$ & $55.9-89.6$ & \\
\hline
\end{tabular}

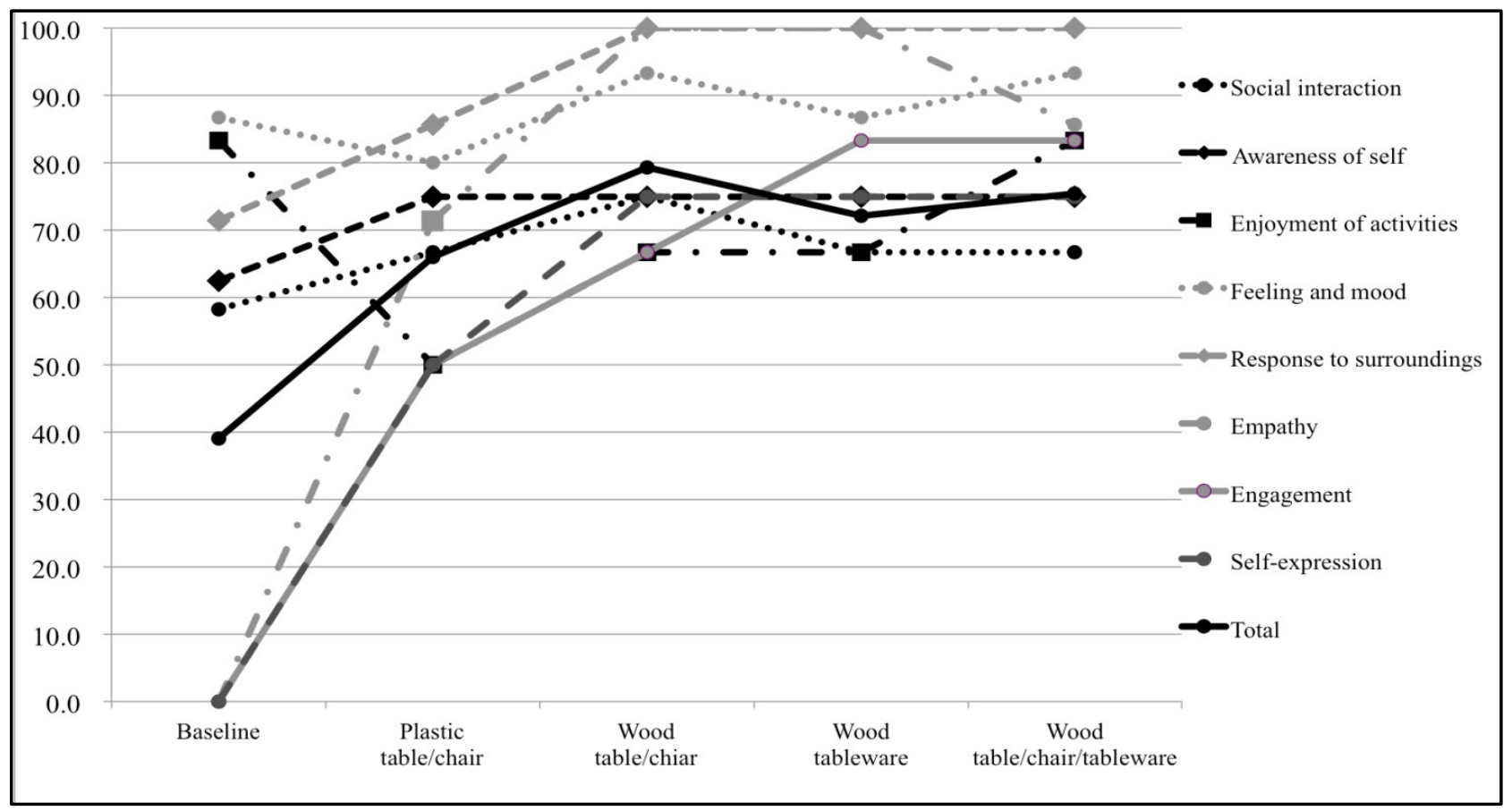

Figure 1. Change in elderly persons' behavior score 


\section{Discussion}

The results indicated that using wood products increased the interaction between the frail elderly, improved emotional relations based on cognitive function, and expanded self-expression in a positive way. For example, they became more talkative, more willing to engage one another. An environment containing wood products greatly increasedthe older persons' mutual interaction and harmonious relations.

This finding is potentially significant for the well-being of the elderly because much previous research has connected social interaction with emotionally rich relationships and has found that chances of self-expression reduce the risk of dementia and health decline[17-20].

Thus, a habitation with wood products may expand the possibility to improve mental and physical abilities for frail elderly. To provide further evidence for the positive effects of wood products, it will be important to evaluate various features of the interaction, such as person-to-person relations, and group activities.

\section{Conclusions}

This studyprovides evidence thatolder persons' behaviors were changed after using wood products, especially increasing positive social interaction. Wood products significantly increased older persons' interaction and level of activity. Thus, the use of wood products may enhance the possibility of preventing mental and physical decline in the frail elderly.

\section{ACKNOWLEDGEMENTS}

We express our deepest respect and gratitude for Director Suzuki and the participants of Oasis Co. This research was supported by the Grants-in-Aid for Scientific Research (23330174, 24653134).

\section{REFERENCES}

[1] SakuragawaS, Miyazaki Y, Kaneko T, Makita T. Influence of wood wall panels on physiological and psychological responses, Journal of Wood Science 51(2), 136-140, 2005

[2] Tsunetsugu Y, Miyazaki Y, Sato H. Physiological effects in humans induced by the visual stimulation of room interiors with different wood quantities, Journal of Wood Science 53(1), 11-16, 2007

[3] Broman NO. Aesthetic properties in knotty wood surfaces and their connection with people's preferences, Journal of Wood Science 47(3), 192-198, 2001

[4] Nakamura M, Kondo T. Quantification of visual inducement of knots by eye-tracking, Journal of Wood Science 54(1),
22-27, 2008

[5] León-Salas, B. et.al. Caregivers' estimation of patients' quality of life (QoL) in Alzheimer's disease (AD):An approach using the ADRQL. Archives of Gerontology and Geriatrics 53(1), 13-18.2011

[6] Zwahlen, RA, et.al. Quality of Life and Psychiatric Morbidity in Patients Successfully Treated for Oral Cavity Squamous Cell Cancer and Their Wives. J Oral Maxillofac Surg. 66(6), 1125-1132. 2008

[7] Anme T, Watanabe T, Tokutake K. A pilot study of social competence assessment using Interaction Rating Scale Advanced (IRSA) , ISRN Pediatrics. doi: $10.5402 / 2011 / 2729132011$

[8] Gresham FM, Elliott SN. Social Skills Rating System - Secondary. Circle Pines, MN: American Guidance Service. 1990.

[9] Caldarella P, Merrell KW. Common dimensions of social skills of children and adolescents: taxonomy of positive behaviors. School Psychology Review, 1997; 26, 264-278.

[10] Elksnin LK,Elksnin N. Teaching social skills to students with learning and behavior problems. Intervention in School \& Clinic, 33(3), 131-141. 1998

[11] Kolb SM, Hanley-Maxwell C. Critical social skills for adolescents with high incidence disabilities: parental perspectives. Exceptional Children,69(2), 163-179. 2003

[12] Riggio ER. Assessment of Basic Social Skills. Journal of Personality and Social Psychology 51(3): 649-660. 1986

[13] Fujimoto M,Daibo K., ENDCOREs: A Hierarchical Structure Theory of Communication Skills, The Japanese Journal of Personality, 15: 347-361. 2007

[14] Rescorla LA. Assessment of young children using the Achenbach system of empirically based assessment (ASEBA). Mental Retardation and Developmental Disabilities Research Reviews, 11:226-237. 2005

[15] Achenbach TM, Becker A. Multicultural assessment of child and adolescent psychopathology with ASEBA and SDQ instruments: research findings, applications, and future directions, Journal of Child Psychology and Psychiatry 49(3): 251-275. 2005

[16] Daniel A, Weinberger DA. Distress and Restraint as Superordinate Dimensions of Self-Reported Adjustment: A Typological Perspective. Journal of Personality58(2): 381-417.1990

[17] Anme T, McCall M. Culture, Care and Community Empowerment: International Applications of Theory and Methods, Kawashima Press, 2008

[18] Anme T, Shinohara R, Sugisawa Y, McCall M. Social Interaction and Longevity: An Eleven-Year Longitudinal Study of Older Persons in a Japanese Village, Hallym International Journal of Aging, 9(2), 89-105, 2007

[19] Fiori KL, AntonucciTC, Cortina KS. Social network typologies and mental health among older adults. Journals of Gerontology: Psychological Sciences, 61B (1): 25-32. 2006

[20] Kempen GI, Ranchor AV, Sonderen E. Risk and protective factors of different functional trajectories in older persons: Are these the same? Journals of Gerontology: Psychological Sciences, 61B (2): 95-101. 2006 